\title{
Green spaces in a tertiary care children's hospital: Benefits, taxonomic survey and perspective
}

\author{
Paulo Cáceres Guido, M.D. ${ }^{a}$, Beatriz G. Varela, M.D. ${ }^{b}$,Hernán G. Bach, M.D. ${ }^{b, c}$, \\ Ziomara Balbarrey, M.D. ${ }^{a}$ and Marcelo L. Wagner, M.D. ${ }^{b}$
}

\begin{abstract}
Humans coming in contact with natural green spaces experience beneficial physical, mental, and social effects. For the primary purpose of describing plant species found in the gardens of Hospital de Pediatría "Prof. Dr. Juan P. Garrahan" (Autonomous City of Buenos Aires), a taxonomic survey was carried out between December 2013 and November 2016. A secondary objective was to review the extent of knowledge on how natural green spaces affect the health of hospitalized patients. There are 69 plant species from 47 botanical families; of these, only $8 \%$ are native. The recommendation is to increase the number of native species and coordinate those aspects related to their preservation. This survey, which is part of a plan that will include the dissemination of knowledge, understanding and awareness of green spaces and health, and the quantification of such specific effects in this hospital, will deepen and promote the interaction of patients, families, and health care providers with natural green spaces.

Key words: environment, hospitals, pediatrics, plants, health.
\end{abstract}

http: / / dx.doi.org/10.5546/ aap.2018eng.e267

To cite: Cáceres Guido P, Varela BG, Bach HG, et al. Green spaces in a tertiary care children's hospital: Benefits, taxonomic survey, and perspective. Arch Argent Pediatr 2018;116(2):e267-e272.

\section{INTRODUCTION}

From the first moment of their existence, humans come in contact with nature in different manners to optimize their survival. The domestication of plants brought about agriculture. The subsequent industrialization of agricultural products unfolded food and drug manufacturing but plants were always associated with recreational urban spaces. From an evolutionary perspective, humans developed as part of a natural environment and physiologically and mentally adapted to it. ${ }^{1}$ Thus, men, as complex information processing organisms, feel useful and pursue happiness by being able to explore and widen their knowledge and skills in their environment. ${ }^{2}$

The current prevalence of noncommunicable diseases, mostly related to lifestyle (cardiovascular disease, stroke, depression, diabetes, obesity, etc.), has become a major public health problem. For this reason, promoting health among urban populations is one of the most intricate health problems of the $21^{\text {st }}$ century. 3,4

A healthy environment is one that offers a variety of restorative activities, which is understood as an enterprise that renews resources and functional capabilities. It should be affordable and accessible, and encourage physical, mental, and social well-being to improve the quality of life of people of the community. ${ }^{5}$

This underpins the principles that state that being in contact with natural environments, given its beneficial effects, is critical for human health.-8

The evidence shows that living in a neighborhood with plenty of green spaces reduces the rate of mortality and aggression among adolescents. During childhood, an adequate contact with nature may provide restorative benefits which, in the long term, build up and create motivation in relation to involvement, risk taking, curiosity, creativity, and strengthening of the sense of self. . $^{1,-11}$

The exposure of children to green spaces has a positive effect on the behavior and cognitive development of schoolchildren., ${ }^{2,8}$

The experience of taking children with different diseases to natural environments started in the mid$20^{\text {th }}$ century, and was widely 
described by the end of the 1980s. One example is horticultural therapy, which was used among adolescents with developmental disorders, children with cerebral palsy or exceptional behavioral disorders, obese patients and those with different psychiatric disorders. ${ }^{12,13}$

Children, even if they are hospitalized, tend to prefer outdoor environments. Such space does not seem to be exclusively determined by aesthetic qualities but by their potential for activities considered fun or pleasant; for this reason, the presence of gardens in health care facilities is enjoying a renaissance. ${ }^{14}$

Likewise, integrating nature into health care improves recovery, shortens the length of stay in hospitals, and reduces medication requirements when patients' rooms have windows overlooking green spaces. ${ }^{5,15-17}$

\section{THE CASE OF HOSPITAL DE PEDIATRÍA "PROF. DR. JUAN P. GARRAHAN"}

Hospital de Pediatría "Prof. Dr. Juan P. Garrahan" was founded in 1987 and stemmed from a project that started in the 1960s, when a group of renown pediatricians from Hospital de Niños "Dr. Ricardo Gutiérrez," headed by Carlos Gianantonio, M.D., developed a medical program for a new pediatric facility model. The proposal was submitted through the Department of Public Health of the Autonomous City of Buenos Aires to the national government. In 1971, the Department of Public Health called for the national presentation of preliminary project drafts. The jury, which was presided by Prof. Dr. José Raúl Vázquez, in representation of the Argentine Society of Pediatrics, and included architects from various public and private organizations, finally selected the project submitted by the studio of architects Vidal, Egoscue, Bischof, Aftalion, Do Porto, and Escudero. ${ }^{18}$

Among other purposes, the original plan highlighted the possibility of providing tertiary care services across all pediatric specialties, which helped the institution become a reference hospital at a national level. ${ }^{18}$

Hospital "Prof. Dr. Juan P. Garrahan" is located in a 9-hectare plot with a built-up area of more than $110000 \mathrm{~m}^{2}$. The building, planned based on the concepts of flexibility and growth, is characterized by its marked horizontal skyline and has three foot traffic sub-systems that are not completely exclusive: 1 . patients and visitors, 2. staff, and 3. supplies. ${ }^{18,19}$

The analysis of the relation between buildings and open spaces shows that the latter have plenty of different plant species which were not originally planned for patients to come in contact with nature but were limited to playing an ornamental and aesthetic role. ${ }^{19}$

At present, Hospital "Prof. Dr. Juan P. Garrahan" has approximately $30000 \mathrm{~m}^{2}$ of green spaces, most of which surrounding the main building. The building is divided into two floors developed along a main axis and connected through ramps with glass walkways that allow looking onto the internal gardens. The staff entrance has external gardens in front and on the sides. The main entrance for patients and visitors and the side of the building are surrounded by large parks. On this side of the building, smaller entrances have been opened in recent years for patients with specific diseases and staff who perform particular tasks. ${ }^{19}$

The hospital's parks and gardens have wide paths only in the area of the patients and visitors entrance. They are located on Pichincha Street, between Brasil Avenue and 15 de Noviembre de 1889 Street, and account for approximately $15 \%$ of all green spaces in the hospital. In the same sector, there are resting areas with concrete structures that serve as seats in the open air.

The maintenance of these green spaces (lawn mowing and trimming, perimeter edges, sweeping, garbage collection and disposal) is done as often as necessary to keep them in the best conditions. Watering, either spaced-out or intensified depending on the season, is performed with water from the general water mains using a hose, a watering can or a bucket, as applicable. Except for a few semi-covered drains, most are uncovered.

The general maintenance also implies replacing highly deteriorated plants by others of the same species.

For the primary specific objective of obtaining an in-depth knowledge of the plant species found in the internal and external gardens of this health care facility and thus optimizing existing natural resource use, every plant species in the hospital was surveyed and identified through observation and digital photography in different months over the study period between December 2013 and November 2016, and herbarium specimens were collected and prepared. A secondary objective was to review the extent of knowledge on how natural green spaces affect the health of hospitalized patients. 


\section{TAXONOMIC SURVEY}

Based on the modern concepts of the environment-patient interrelation, and as part of a joint wider collaboration, a team of professionals from the Chair of Pharmacobotany of the School of Pharmacy and Biochemistry (Universidad de Buenos Aires, Argentina) and from the Integrative Medicine Group of Hospital de Pediatría “Prof. Dr. Juan P. Garrahan" conducted a taxonomic survey of the plant species found in this health care facility of the Autonomous City of Buenos Aires.

Most species in the hospital are striking because of their lush foliage, varying colors or flower fragrances, which are modified especially in the fall. Tree species stand out because of the shape of their tops or branches and the texture of their barks.

Plant taxonomy is used to obtain a hierarchized and systematic arrangement of plant groups and is a critical tool to validate species identification..$^{20}$

The Catálogo de las Plantas Vasculares del Cono $\mathrm{Sur}^{21}$ was used to establish the taxonomy of native species.

There are 69 different plant species (not specimens) across the internal and external gardens of Hospital "Prof. Dr. Juan P. Garrahan." The number of specimens has decreased over the years for different reasons, such as specimen deterioration due to drought, disease or removal to carry out building alterations.

Species may be classified into herbs (herbaceous plants), shrubs and trees. There are 14 herbaceous species, 20 shrub species, and 35 tree species.

Approximately three quarters of trees are located in the external gardens.

The 69 plant species included in the survey account for 47 botanical families. Almost all species belong to the Angiospermae or Magnoliophyta division ("flowering and fruiting plants") and only a few are in the Gymnospermae or Pinophyta division.

Thus, there are 45 Angiospermae families and only 2 in the Gymnospermae family. Among the former, most are dicotyledons (39) and the rest (6), monocotyledons. In general, dicotyledons belong to the Rosaceae and Fabaceae families.

The internal gardens have a few species that may be toxic but, given their location, patients and caregivers are not allowed to come in contact with these. Below follows a list of scientific names with the most frequent common names between brackets. Juniperus communis (Coniferae family), "common juniper"; Ficus benjamina (Moraceae family), "weeping fig"; Phormium tenax (Xanthorrhoeaceae family); Nerium oleander (Apocynaceae family), "oleander"; and Melia azedarach (Meliaceae family), "chinaberry tree". ${ }^{22}$

Five species at least have related medicinal uses: Juniperus communis (Coniferae family), "juniper"; Eucalyptus cinerea (Myrtaceae family), "silver-leaf stringybark "; Citrus aurantium (Rutaceae family), "bitter orange"; Phytolacca dioica (Phytolaccaceae family), "Bella sombra tree"; and Tilia moltkei (Malvaceae family), "linden". ${ }^{23}$

At least six species produce edible fruits: Ficus carica (Moraceae family), "common fig"; Citrus reticulata (Rutaceae family), "mandarin orange"; Cydonia oblonga (Rosaceae family), "quince"; Morus alba (Moraceae family), "white mulberry"; and Persea americana (Lauraceae family), "avocado". ${ }^{24}$

Out of 35 tree species, only $8(22 \%)$ are native (indigenous) to our geographic area or regional ecosystem. They come from the Northwest, Northeast (eastern Chaco and Mesopotamia), and Central regions of Argentina.

\section{Native species}

Plant species native to the hospital are Erythrina crista-galli (Fabaceae family), "cockspur coral tree" and national flower of Argentina and Uruguay; Jacaranda mimosifolia (Bignoniaceae family), "blue jacaranda"; Phytolacca dioica (Phytolaccaceae family), "Bella sombra tree"; Copernicia alba (Arecaceae family), "Caranday palm"; Ceiba chodatii (Bombacaceae family), "floss silk tree"; Ceiba speciosa (Bombacaceae family), "pink floss silk tree"; Celtis ehrenbergiana (Cannabaceae family), "desert hackberry"; and Tipuana tipu (Fabaceae family), "tipa".

\section{Exotic species (introduced species living outside their native distributional range)}

These may sometimes be rather invasive because they modify the ecosystem and environment and, for this reason, they should be located strategically and carefully monitored.

Exotic trees identified at Hospital "Prof. Dr. Juan P. Garrahan" are native to the Northern Hemisphere (Canada, United States, and Mexico), Central America, Europe, Asia (China, Japan, the Himalayas), and Oceania (Australia and New Zealand).

\section{DISCUSSION}

Hospital "Prof. Dr. Juan P. Garrahan" is a member of the Global Green and Healthy 
Hospitals Network, a global initiative that is part of the Health Care Without Harm movement, whose purpose is to support the existing efforts aimed at promoting a higher level of sustainability and environmental health in the health care setting and strengthen health care systems worldwide. This initiative includes aspects such as infrastructure and space management, and member hospitals must comply with environmentally relevant objectives. ${ }^{25}$

According to Patricio Garrahan, M.D., the son of Dr. Juan P. Garrahan, his father dreamed of building a children's hospital with green spaces in the form of a botanical garden including native trees and medicinal plants inside the old Hospital de Clínicas "José de San Martín" in the Autonomous City of Buenos Aires. ${ }^{26}$

A well-designed garden, including plant types and distribution, exposure to the open air, a bright environment, colors, shades, the sound of water, and resting areas altogether may have a positive impact on the well-being of people coming and going to the hospital, either patients, caregivers or health care staff. In addition, it is also important to train patients, families, caregivers, and hospital staff on the importance of a garden and its adequate maintenance. ${ }^{27}$ In every case, always considering biosafety recommendations related to each element and type of patient. For example, fountain water conditions to prevent the growth of disease-transmitting mosquitoes, among other things. ${ }^{28}$

Gaining a detailed knowledge of existing species in the hospital's natural green spaces is the first step, and this together with a strategic plan based on people's interaction with nature (in different modalities), may help to improve the well-being and health of patients, caregivers and health care staff.

Besides the benefits of green spaces that have been described, these places may be used as part of occupational-horticultural therapy with the setup of demonstration vegetable gardens or nurseries that provide plants to substitute those at the hospital. Thus, patients well enough to receive this therapy may be in direct contact with nature and help to maintain the gardens. ${ }^{12}$

The diverse plant species may be seen and enjoyed in different manners but during the flowering season they create a landscape that is positive and stimulating for the senses, so it is critical to arrange for their maintenance, thus generating an adequate framework for the internal and external hospital spaces. ${ }^{15}$
The survey of the hospital's plant species may become a primary source of information and subsequently raise awareness in relation to the importance of green spaces for patients, caregivers, and hospital staff. ${ }^{5}$

It is worth noting that, at present, there are projects for the renovation and adaptation of the hospital's green spaces in collaboration with governmental, academic, and non-governmental organizations that may provide the adequate motivation for the distribution of new natural green spaces. In this context, a larger number of plant species native to Argentina should be introduced.

Continuing the work described in this article will provide a better knowledge of existing plant species and thus promote a plan that will facilitate the interaction of patients, families, and staff with the gardens and, probably, even contribute to their maintenance and care.

Together with the projects for the renovation and adaptation of the hospital's green spaces, future studies are required to gather further information on the relationship between green spaces and health, especially among hospitalized pediatric patients with complex and chronic diseases, and those involved in their treatment and care.

\section{Acknowledgments}

We would like to thank the members of the Integrative Medicine Group, especially Adriana Macchi, M.D., who made substantial corrections to the final draft of this article.

\section{REFERENCES}

1. Berto $R$. The role of nature in coping with psychophysiological stress: a literature review on restorativeness. Behav Sci (Basel) 2014;4(4):394-409.

2. Driver BL, Greene P. Man's nature: innate determinants of response to natural environments. In Children, Nature, and the Urban Environment, USDA Forest Service Report NE-30. Upper Darby, PA: Northeastern Forest Experiment Station; 1977.P.63-70.

3. GBD 2015 Risk Factors Collaborators. Global, regional, and national comparative risk assessment of 79 behavioural, environmental and occupational, and metabolic risks or clusters of risks, 1990-2015: a systematic analysis for the Global Burden of Disease Study 2015. Lancet 2016;388(10053):1659-724.

4. Soga M, Gaston KJ, Yamaura Y. Gardening is beneficial for health: A meta-analysis. Prev Med Rep 2016;5:92-9.

5. Anderson JE. Actions Underway - Healthcare Providers. In: Gentry B, Anderson J, Krause D, et al. Improving human health by increasing access to natural areas: linking research to action at scale. Connecticut: Yale School of Forestry \& Environmental Studies; 2014.P.25-38.

6. de Sarasqueta P. ¿Pensamos en el medio ambiente? Med Inf. 2004;11(3):179. 
7. Lejarraga $\mathrm{H}$. Heredabilidad y medioambiente en al desarrollo del niño. Arch Argent Pediatr 2010;108(6):532-7.

8. Dadvand P, Nieuwenhuijsen MJ, Esnaola M, et al. Green spaces and cognitive development in primary school children. Proc Natl Acad Sci USA 2015;112(26):7937-42.

9. Hartig T, Staats H. Guest editors' introduction: Restorative environments. J Environ Psychol 2003;23:103-107.

10. Hartig T, Mitchell R, de Vries S, et al. Nature and health. Annu Rev Public Health 2014;35:207-28.

11. Collado S, Staats H. Contact with Nature and Children's Restorative Experiences: An Eye to the Future. Front Psychol 2016;7:1885.

12. Söderback I, Söderström M, Schälander E. Horticultural therapy: the 'healing garden' and gardening in rehabilitation measures at Danderyd Hospital Rehabilitation Clinic, Sweden. Pediatr Rehabil 2004;7(4):245-60.

13. Pringuey-Criou F. Healing garden: Primary concept. Encephale 2015;41(5):454-9.

14. MitrioneS. Therapeutic responses tonatural environments: using gardens to improve health care. Minn Med 2008;91(3):31-4.

15. Maas J, Verheij RA, Groenewegen PP, et al. Green space, urbanity, and health: how strong is the relation? J Epidemiol Community Health 2006;60(7):587-92.

16. PrescottSL, Logan AC. Transforming Life: ABroad View of the Developmental Origins of Health and Disease Concept from an Ecological Justice Perspective. Int J Environ Res Public Health 2016;13(11):E1075.

17. Ulrich RS, Simons RF, Losito BD, et al. Stress recovery during exposure to natural and urban environments. $J$ Environ Psychol 1991;11:201-30.

18. Hospital de Pediatría Prof. Dr. Juan P. Garrahan: Historia. Ciudad Autónoma de Buenos Aires; 2017. [Accessed on: July 3rd, 2017]. Available at: http:/ / www.garrahan.gov. ar/historia/contenidos/historia.

19. Ottaviani E. Los espacios abiertos en los hospitales, como instrumento del cuidado de la salud y la integración social.
Caso de Estudio: Hospital Nacional de Pediatría “Prof. Dr. Juan P. Garrahan". [Dissertation] Buenos Aires: Facultad de Arq. y Urb. (UBA); 2003.

20. Bussmann RW. Taxonomy - An Irreplaceable Tool for Validation of Herbal Medicine. In: MukherjeePK. EvidenceBased Validation of Herbal Medicine. Oxford: Elsevier; 2015.P.87-118.

21. Instituto de Botánica Darwinion. Catálogo de Plantas Vasculares del Cono Sur. [Accessed on: July 3rd, 2017]. Available at: http://www.darwin.edu.ar/Proyectos / FloraArgentina/fa.htm.

22. Pérez Cuadra V, Cambi V, Rueda MA, et al. Consequences of the Loss of Traditional Knowledge: The risk of injurious and toxic plants growing in kindergartens. Ethnobotany Research and Applications 2012;10:077-094.

23. González-Tejero MR, Casares-Porcel M, Sánchez-Rojas $\mathrm{CP}$, et al. Medicinal plants in the Mediterranean area: synthesis of the results of the project Rubia.J Ethnopharmacol 2008;116(2):341-57.

24. Mariaca Méndez R. El huerto familiar del sureste de México. Secretaría de Recursos Naturales y Protección Ambiental del Estado de Tabasco y El Colegio de la Frontera Sur. Tabasco: ECOSUR; 2012.

25. Global Green and Healthy Hospitals. Members around the world. Health Care Without Harm. [Accessed on: July 3rd, 2017]. Available at: www.greenhospitals.net/ members $/$ ?lang=en.

26. Ciencia en la vidriera. Personaje del mes: Juan P. Garrahan. [Accessed on: July 3rd, 2017]. Available at: http:/ / www. cienciaenlavidriera.com.ar/2009/09/01/garrahan-juanp-personaje-recordado-del-mes-septiembre-2009/.

27. Whitehouse S, Varni JW, Seid M, et al. Evaluating a children's hospital garden environment: utilization and consumer satisfaction. J Environ Psychol 2001;21(3):301-14.

28. Heukelbach J, de Oliveira FA, Kerr-Pontes LR, et al. Risk factors associated with an outbreak of dengue fever in a favela in Fortaleza, north-east Brazil. Trop Med Int Health 2001;6(8):635-42. 